\title{
Nuclear Power Plant Accident
}

National Cancer Institute

\section{Source}

National Cancer Institute. Nuclear Power Plant Accident. NCI Thesaurus. Code C120582.

A release of nuclides and radiation at a nuclear power plant that has led to significant consequences to people, the environment or the facility. 